\title{
LIDERAZGO Y COMUNICACIÓN: PROLEGOMENO REFLEXIVO PARA ESCUELAS DE ENFOQUE INCLUSIVO
}

Leadership and communication: reflective preface for schools inclusive approach Liderança e comunicação: reflexivo prefácio para escolas abordagem inclusivo

\section{Sergio Manosalva Mena}

Universidad Andrés Bello, Chile. Telf.: +569 88081 306. Correo electrónico: dr.manosalvamena@gmail.com

\section{Resumen}

En el presente artículo pretendo mostrar las bases iniciales del liderazgo y la comunicación desde la perspectiva teórica sistémica de Niklas Luhmann y la epistemología de la biología del conocer de Humberto Maturana, para iniciar una reflexión en torno a escuelas de enfoque inclusivo.

Al abordar el tema del liderazgo, se me hace altamente imprescindible acotar una definición del mismo, y desde ahí entrar a describir la comunicación como la capacidad basal autopoietica en la viabilidad de todo sistema social, sea o no productivo, tenga o no fines de rentabilidad. Esta distinción me permite levantar la tesis de que todo líder debe operar con un alto grado de inteligencia comunicativa para conservar la viabilidad adaptativa de un sistema social y, en particular, en los sistemas educativos que al ser siendo en la diversidad, deben ampliar su espectro comunicativo más allá de sus fronteras. Condición sine qua non para ser inclusivos.

Palabras clave: liderazgo, pedagogía, comunicación, educación inclusiva.

\begin{abstract}
In this article I intend to show the bases initial communication from the systemic theoretical perspective of Niklas Luhmann and epistemology of the biology of learning and leadership of Humberto Maturana, to initiate a reflection on schools on inclusive approach.
\end{abstract}


Addressing the theme of leadership, is me highly essential to narrow a definition of the same, and from there enter to describe communication as the basal capacity autopoietic in the viability of entire social system, whether or not productive, have or not purposes of profitability. This distinction allows me to lift the thesis that every leader must operate with a high degree of communicative intelligence to preserve Adaptive social system and viability, particularly in educational systems that to be still in the diversity, must expand your communicative spectrum beyond their borders. Sine qua non condition to be inclusive. Key words: leadership, pedagogy, communication, inclusive education.

\section{Resumo}

Neste artigo eu pretendo mostrar as bases de comunicação inicial da perspectiva teórica sistêmica de Niklas Luhmann e epistemologia da biologia da aprendizagem e liderança de Humberto Maturana, para iniciar uma reflexão sobre as escolas de abordagem inclusivo.

Abordando o tema da liderança, é me altamente essencial para estreitar uma definição do mesmo e de lá entrar para descrever a comunicação como a basal capacidade autopoiética na viabilidade de todo o sistema social, produtiva ou não, ter ou não fins de rentabilidade. Esta distinção permite-me a levantar a tese de que cada líder deve operar com um alto grau de inteligência comunicativa para preservar sistema social adaptativo e viabilidade, particularmente nos sistemas educacionais que estar ainda na diversidade, deve expanda seu espectro comunicativo para além das suas fronteiras. Condição sine qua non para ser inclusivo.

Palavras-chave: liderança, pedagogia, comunicação, educação inclusiva

\section{1.- Introducción}

Deseo hacer una breve distinción relacionada con tres significados asociados entre sí: Liderazgo, Liderar y Líder y tres concepciones de corte ontológico y epistemológico que también se relacionan entre sí: Tener, Hacer y Ser.

El líder es quien tiene la capacidad de conducirse a sí mismo, y conducir a un grupo de personas hacia un objetivo común; va más allá de los propios intereses; tiene conciencia de sí mismo y de los demás; posee convicción, anticipación y comunicación clara y 
efectiva. Las características señaladas le permiten generar seguridad y confianza para que sus seguidores se hagan parte y asuman un proyecto común.

El líder es un individuo creador de una historia que gatilla significativamente los pensamientos, conductas y sentimientos de un número significativo de personas (llamadas colaboradores). Así, un líder solo puede ser efectivo si su historia es poderosa (Gardner, 1998). De este modo, al líder lo podemos situar con el ser.

Una de las principales herramientas del líder en su acción de liderar es establecer una buena relación con otros, en definitiva saber relacionarse con otros en un proceso social que implica la comunicación; es más, la comunicación es la base misma de la condición de un líder (Veliz, 2011).

Según un estudio realizado en España (Folkman y Zenger, 2002), la comunicación y las habilidades emocionales son tareas urgentes de desarrollar en los líderes organizacionales, puesto que ello hace la diferencia entre ser jefe y ser líder (Sandoval, 2016). De acuerdo a las conclusiones de este estudio: "La habilidad de comunicarse tiene beneficios múltiples: un líder si sabe qué, cuándo y cómo comunicar multiplica el compromiso de sus empleados y con ello la capacidad de innovación y generación de resultados de la empresa. Sin duda, los buenos líderes son buenos comunicadores; ellos consiguen mayor rentabilidad, menor rotación de personal, logrando que el equipo se involucre, se comprometa y llegue a las metas".(Para esta y otras informaciones, se puede consultar en la página http://www.grupopya.com/es/partner/zenger-es-es-es/).

Una buena comunicación viene a ser el hacer de un líder. En tanto liderazgo viene a ser el tener de un líder.

Este tercer concepto (liderazgo) es de difícil abordaje y definición puesto que es plurisemántico o multisignificativo. Significa distinto para diferentes personas, lo que acarrea ambigüedad en torno a su significado. Entre las tantas definiciones con las que se trata de explicar el significante, me quedo con la descrita por Tannenbaum, Weschler y Massarick (1971) que la definen como "la influencia interpersonal, ejercida en una situación y dirigida a través de procesos de comunicación, hacia una meta o metas 
específicas". Definición que (demás está decir), la recorto según mis propios intereses y paradigmas de base.

\section{2.- Distinciones entre líder, liderar y liderazgo}

Dando un esbozo muy general y un tanto superficial de los tres conceptos, puedo decir que ser líder tiene relación con el ser, liderar con las acciones (hacer) y liderazgo con los resultados o el tener. De lo que resulta un esquema que permite reflexionar y emitir juicios para la toma de decisiones de cada una de estas dimensiones en una relación sistémica con las otras.

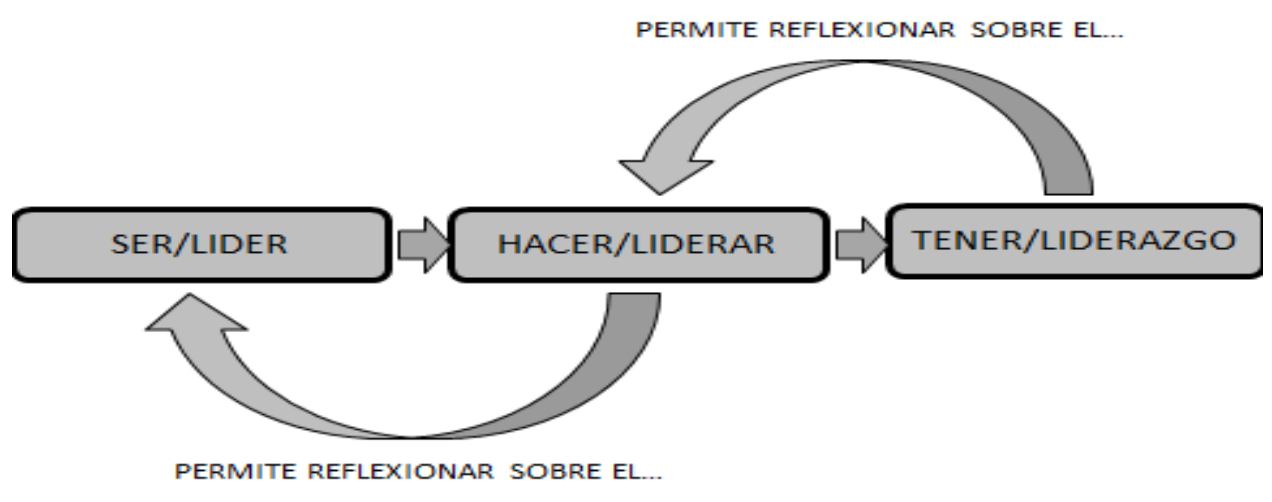

Este esquema permite visualizar que es en la acción donde se debe poner el foco de las observaciones, puesto que un líder es reconocido por su liderazgo (producción), de donde podemos concluir resultados, pero no el proceso. Y por otra parte, al líder lo reconocemos por los atributos que se le han asignado al operar en consecuencia y coherencia con ciertas características distintivas. Dicho en otras palabras, se sustantiva o se genera una identidad de una clase particular de individuo en el cual o en la cual se puede reconocer una congruencia entre comportamientos, actitudes, expectativas, sentimientos, pensamientos, valores y creencias puestas en acción para un objetivo centrado en la alteridad (el otro o lo Otro que no es el Yo) y del cual soy responsable (Lévinas, 2006).

Si aceptan mis proposiciones explicativas, entonces se puede decir que en todo sistema social la comunicación es la que cobra el mayor sentido para definir las 
características con las que podemos distinguir esa identidad. Es más, sólo la realización de unas determinadas comunicaciones permite la viabilidad de un sistema social determinado. Al dejar de existir las comunicaciones, el sistema social muere como tal.

Aquí se me hace necesario incluir un concepto relacionado con los sistemas sociales en tanto influyen en su constitución, pero no los determinan. Me refiero al entorno. Es decir, todo sistema social posee una organización que lo diferencia del entorno, y con el cual mantiene una relación de acoplamiento necesaria para su viabilidad. Este acoplamiento entre sistema social y entorno permite diferenciar los sistemas sociales animales de los sistemas sociales humanos.

Para hacer una diferenciación muy somera entre sistemas sociales animales y sistemas sociales humanos, recurriré a una distinción que hizo Konrad Lorenz (1995) al diferenciar el determinismo animal del determinismo humano. Lorenz nos señaló que todo lo que define a un miembro de una especie animal en particular, está dado en sus genomas; y todo lo que requiere un cachorro de la especie humana para ser miembro de la especie humana, está dado en la cultura. Si me sostengo en esta teoría, puedo señalar que un buen líder se debe caracterizar por su capacidad para sensibilizar respecto a la importancia de los cambios culturales (entorno) para la viabilidad del sistema social humano (comunicaciones). Así, todo líder debe ser un experto en endo-comunicación y exocomunicación. Por ello, sin comunicación no hay líder.

Una comprensión de la relación entre liderazgo y comunicación, requiere de un planteamiento teórico que la sostenga. En ese camino me referiré a las bases teóricas de Luhmann (1998; 1990), quien se sustenta en los planteamientos epistemológicos de Maturana y Varela. Ello me lleva a realizar algunas distinciones al respecto.

\section{3.- Organización y estructura}

Para comprender estos dos conceptos, Maturana (1992) nos hace una reflexión de los tipos de unidades o talidades que distinguimos en el acto de observar. Nos habla de unidades simples y unidades compuestas.

Cuando distinguimos una unidad simple, estamos haciendo referencia a una totalidad sobre la cual no realizaremos otras operaciones de distinción; es decir, una unidad 
simple queda caracterizada en su totalidad, sin descomponerla en sus elementos que la constituyen como un todo; queda así caracterizada por la propiedad con que la diferenciamos. Cuando distinguimos unidades compuestas, realizamos dos tipos de operaciones consecutivas: primero, caracterizamos la totalidad como una unidad simple y, luego, hacemos distinciones de los elementos que la constituyen como totalidad; es decir, realizamos un acto de descomposición de la unidad que estamos observando.

Así, la distinción de la unidad simple o compuesta depende de las operaciones que realicemos en el acto de observar tal o cual totalidad. Si tomamos una unidad simple y la descomponemos en los elementos que la constituyen, observaremos una unidad compuesta; es decir, habremos realizado un cambio de organización de los elementos que la constituyen como una unidad de una clase particular; la hemos desintegrado como totalidad que distinguíamos antes de descomponerla en los elementos que la constituían como unidad.

Tenemos, entonces, elementos que pertenecían a una determinada unidad; o dicho de otro modo, componentes que ahora no están relacionados de una manera particular que permitan la observación de la organización que distinguíamos perteneciendo a una clase particular; así, perdió su identidad de clase. De esta manera, la noción de organización está referida a la relación específica de los componentes de una unidad compuesta que permite distinguir su identidad de clase que hemos construido para ella. Y, la noción de estructura se refiere a los componentes y sus relaciones que permiten la realización de la organización de una unidad específica.

\section{4.- Determinismo estructural}

Cuando observamos una unidad y hacemos referencia a su identidad de clase particular a la que pertenece, nos estamos refiriendo a su organización, pues si cambia la organización cambia la identidad de clase de la unidad que ahora distinguimos en el acto de observar. Así, la organización de una unidad total no cambia, no varía, pues si variara ya no tenemos la unidad que distinguíamos antes de que variara. Lo que varía, y es necesario que lo haga para el mantenimiento de la organización, es la estructura. 
Los múltiples cambios observados en una unidad viva son variaciones estructurales que se posibilitan por la condición de sus mismos elementos o relaciones entre ellos. Por lo tanto, toda unidad viva está determinada en su estructura, no en su organización.

Es la determinación de la estructura de toda unidad viva la que posibilita su operación como totalidad ya que, cuando un sistema interactúa, lo hace a través de sus componentes y sus relaciones que la constituyen como una organización particular. Es decir, el dominio de interacciones de un sistema vivo está especificado por su organización, pero la realización de sus interacciones está determinada por sus componentes y su modo particular en que están relacionados. Por lo tanto, nada de lo que ocurra fuera de un sistema vivo puede modificar su manera particular de existencia.

Todo sistema vivo modifica la realización particular de sus interacciones en tanto haya modificación de sus elementos y relaciones de elementos (estructura) que constituyen su identidad. Esta modificación de su estructura no le viene desde fuera, sino que lo externo sólo desencadena cambios en los elementos y relación de elementos que están determinados en su propia configuración particular. Esto es determinismo estructural.

\section{5.- Organización autopoiética}

Todo sistema vivo se caracteriza por su organización particular que la define perteneciendo a una clase determinada. Si cambia la organización, se produce una variación de la identidad de clase del sistema vivo que distinguíamos antes del cambio. En otras palabras, podemos entender que un cambio en la organización de un sistema, es su destrucción, su muerte como perteneciente a una clase particular. Por lo tanto, lo que caracteriza a un sistema vivo es su organización. Mientras se mantenga su organización se mantiene su existencia. Esta característica de los sistemas vivos - de mantener su organización en la conservación de su vivir- es lo que Maturana y Varela (1972) distinguen como "organización autopoiética". Esta organización autopoiética, característica de los seres vivos, permite la producción de elementos y nuevas relaciones de elementos que especifican la unidad viva. Así, toda unidad viva es autónoma y auto-organizada.

Según Maturana y Varela (1972) la organización autopoiética significa simplemente procesos concatenados de una manera específica tal que los procesos concatenados producen los componentes que constituyen y especifican al sistema como unidad. Esta es la 
distinción fundamental entre los sistemas vivos y sistema no vivos. La existencia de sistemas o unidades no vivas se realiza en un dominio de relaciones entre componentes, en cambio la existencia de sistemas vivos se realiza en un dominio de relaciones de producción de sus componentes.

Esta característica de los sistemas vivos, permite distinguirlos como unidades o sistemas cerrados; es decir, la capacidad de auto-organización de un sistema vivo en la conservación de su unidad, está determinada en su propia estructura que permite su realización; no es determinada fuera de su unidad total; las estructuras se van modificando por medio de cambios desde el interior de los mismos.

\section{6.- Sistemas sociales}

Luhmann (1997) utiliza esta teoría de la autopoiésis para caracterizar los sistemas sociales. Explica que los sistemas sociales constituyen en sí mismos los elementos para su autoconservación. Este elemento es para Luhmann la comunicación. Toda sociedad genera una cultura que expresa una red de comunicaciones definidas, que determinan un modo de vivir particular dentro de ese sistema social. Este planteamiento de que los sistemas sociales están compuestos de comunicaciones y no de seres humanos, ha gatillado controversias por diferencias teóricas de base, sustentadas en plataformas paradigmáticas antagónicas.

Luhmann sostiene que existen tres tipos fundamentales de sistemas auto-referentes: los sistemas vivos, los sistemas psíquicos y los sistemas sociales, donde atribuye la comunicación como el rasgo característico este último. Así, él dice que los sistemas sociales siguen sus propias reglas con independencia de los seres humanos.

En contraposición de este planteamiento, sostengo que somos los seres humanos quienes, bajo una concepción particular de convivencia, construimos nuestras reglas de interacción, en coordinación de conductas comprensibles para los que participan de estas redes conductuales. Para mí, lo social es una abstracción de un tipo particular de convivencia que, consciente o inconscientemente, es construida por los seres humanos y es transmitida recursivamente por medios materiales e inmateriales a los nuevos integrantes de ese grupo social, quienes las aceptan para mantener los vínculos y construir su identidad. 
Todo sistema social es un sistema de convivencia que se especifica en una emoción básica. Esta emoción básica es el amor. La emoción del amor expresada como "respetar al otro como un legítimo otro en la convivencia con uno" (Maturana, 1992). Al respecto, Maturana sostiene que tenemos sistemas sociales y sistemas no sociales. Los sistemas sociales son sistemas de convivencia constituidos bajo la emoción del amor. Los sistemas no sociales están constituidos bajo una emoción distinta, que puede ser de compromiso. Los sistemas no sociales están constituidos bajo la negación del otro o de sí mismo por el sometimiento a un orden jerárquico. Se da una dinámica de orden y obediencia.

Estos conceptos son gravitantes a la hora de cuestionar el sistema educacional, pues el objetivo de las escuelas es propiciar desarrollo humano, pero la escuela es un sistema tradicionalmente basado en relaciones de negación y obediencia.

Las escuelas, más que trabajar con el presente de los seres humanos, establece relaciones de asimilación del otro. Niega al otro como legitimo otro en la convivencia, al instaurar relaciones donde el estudiante debe responder a un deber ser, para un futuro incierto (Maturana, 1992). De este modo nunca se está con el presente del otro. Se deslegitima al otro en un convivir negando la existencia del otro, que es lo mismo que negar la coexistencialidad.

\section{7.- Comunicación y Sistemas Sociales}

Tomando de base a Niklas Luhmann, puedo expresar que los sistemas sociales, cualquiera sea, son sistemas que se constituyen, se hacen, se construyen, por diferenciación autorreferencial con un entorno (todo lo que está fuera de los límites de ese sistema, todo lo que no es y con el que se está siendo) con el que se interrelacionan en un acoplamiento estructural, en una danza de sentidos, que observamos mientras los sistemas conservan su viabilidad. De lo que resulta que, para conservar su viabilidad, todo sistema social debe mantener y autoproducir las comunicaciones que le son distintivas y le dan sentido como identidad operacionalmente cerrada. De este modo, lo que distingue a los sistemas sociales son las comunicaciones que los mismos sistemas se encargan de producir y reproducir.

Estas (las comunicaciones) otorgan la realización de uno de los tres tipos de sistemas sociales que describe Luhmann: interacciones, organizaciones y sociedades. De donde, dependiendo de las comunicaciones, podemos distinguir diversidad de sistemas 
sociales. Luhmann se refiere a los Sistemas Sociales como entidades auto-referencialmente constituidas. En ellas existe clausura y apertura operacional comunicativa.

Veamos cómo explica el autor lo que entiende por comunicaciones, para luego ligar con la constitución de diversidades de tipos de sistemas sociales que se realizan en la conservación de comunicaciones paradigmáticas diferentes.

Para Luhmann, la comunicación es la operación específica de los sistemas sociales; estos se constituyen por una relación de doble contingencia, donde están presentes la emisión, la información y el acto de entender; es decir, existe comunicación toda vez que se emite una información con comprensión de la información emitida, siendo la comprensión el fundamento de la comunicación y premisa para una nueva comunicación.

De la definición anterior se desprende que, en toda comunicación se puede distinguir la indisociable, indivisible, conformación de sus tres componentes que la constituyen como un evento que desaparece en cuanto aparece: emisión, información, comprensión. Por lo tanto, para la conservación de un sistema social, cualquiera sea, se requiere continuidad de una secuencia recursiva, con sentido, dentro de un proceso identitario del sistema social que distinguimos en el acto de observar. Independientemente que la observación la realicemos como sistemas psíquicos o sistemas sociales.

Al observar como sistema social, lo que se observa se convierte en tema de comunicación y da sentido al sistema social que interacciona con su entorno en tanto mantenga una red recursiva de comunicaciones. Esta relación entre sistema y entorno se ha definido como acoplamiento estructural. Acoplamiento absolutamente necesario para la viabilidad del sistema, pues, de no darse, el sistema deja de existir. Sin embargo, entre el sistema social y su entorno no existe comunicación, sino sólo perturbaciones que permiten la producción de las comunicaciones al interior del sistema social y, con ello, su conservación. Podemos decir, entonces, que sistema social y entorno se requieren, se permiten, se autoconstituyen siempre en relación a lo Otro "lo diferenciado y lo indiferenciado" respecto de las comunicaciones que distinguen a un tipo de sistema social determinado, según nuestras distinciones o las autodistinciones del sistema social.

Dependiendo de lo que se observa del entorno, una perturbación se puede configurar como información que posibilita un cambio de estructura en el sistema social. Por tanto, 
una misma operación puede tener (y tiene) significados distintos según el sistema funcional en que se realice tal distinción.

Luhmann, dentro de esta misma línea, sostiene que, existen tres tipos fundamentales de sistemas auto-referentes: los sistemas vivos, los sistemas psíquicos y los sistemas sociales. Explica que los sistemas sociales constituyen en sí mismos las comunicaciones como elementos para su auto-conservación. Toda sociedad genera una cultura que expresa una red de comunicaciones definidas, que determinan un modo de vivir particular de ese sistema social. Así, él dice que los sistemas sociales siguen sus propias reglas con independencia de los seres humanos. Es decir, sistemas sociales y sistemas humanos existimos en una relación dialéctica auto-constituyente, donde las modificaciones en la estructura sólo se dan por acción misma de sus propios componentes, en tanto el entorno únicamente provoca una posibilidad de cambio estructural; posibilidad que se encuentra determinada sólo, irrenunciablemente e indescifrablemente, en el propio sistema.

De esta forma distinguimos un sistema social y sus componentes y relaciones de componentes que lo posibilitan, que lo visibilizan, que lo conforman para un observador. Elementos y relaciones de elementos que se ha denominado estructura, pero que sólo podemos observar si hacemos la distinción de una organización como unidad compuesta.Estos componentes y relaciones de componentes se van reproduciendo a sí mismos para conservar la viabilidad del sistema social que reconocemos perteneciendo a una clase particular. Si por alguna razón los componentes y/o relaciones entre los componentes dejan de reproducirse a sí mismos, el sistema social total cambia y con ello pierde su identidad de clase distintiva.

Como todo sistema social es autopoiético, reproducen en sí mismos (determinismo estructural) los componentes que los constituyen para la viabilidad del sistema social. De este modo, la apertura y clausura operacional permite la conservación de las comunicaciones para el mantenimiento de la organización, pero a la vez requiere de cierta transformación de sus elementos para la conservación de su viabilidad. Con esta distinción, puedo decir que cada institución, posee su propia identidad única e irrepetible, mientras conservan las comunicaciones que las hacen pertenecientes a la clase particular de Sistemas Sociales que distinguimos en el acto de observar. 
Así, podemos hacer una alusión al libro “La Quinta Disciplina” (Senge, 2005), con la siguiente analogía: somos prisioneros de las comunicaciones que constituyen a un determinado sistema social, de donde cada uno de nosotros es parte de la estructura total sistema- que funciona según el paradigma holístico y que podemos explicar con la teoría del caos para hacer referencia a los modelos mentales de funcionamiento de un determinando sistema social (interrelaciones, organizaciones o sociedades). De este modo, si un líder debe impulsar un cambio dentro de una organización tendrá que actuar en dos dimensiones o planos: el cognitivo (en la construcción de significados compartidos) y el emocional (en la generación de empatía o sintonía emocional). En este segundo plano o dimensión, podemos entrar en las propuestas explicativas de la inteligencia emocional descrita por Gardner (2015).

\section{8.- Comunicaciones y sistemas sociales}

Debo partir diciendo que entiendo toda interacción humana esencialmente como un acto de comunicación simbólica que adquiere diferentes connotaciones según los significados y los valores de quienes intervienen en el proceso. O dicho de otro modo: puedo saber algo de lo que estoy comunicando, pero no puedo saber lo que el otro comunica, pues toda lectura se hace desde las experiencias personales que cargan a las palabras de innumerables sentidos. De este modo las palabras no son neutras para quien las dice y para quien las escucha, pero aún hay más, las palabras se distorsionan según el canal que se utilice para su transmisión. Un YO quiere decir A, pero sale B y luego el OTRO escucha C. El OTRO responde X, pero sale Y y el YO escucha Z.

Así graficado, todos ilusionamos decir lo que queremos decir e ilusionamos escuchar lo que el otro quiso que escucháramos. Pero, ni el que quiso decir dijo lo que quiso decir, ni el que escuchó pudo escuchar lo que se dijo. Tal vez sólo nos queda un acto de confianza o el juego difícil de ser en una doble hermenéutica (Ricoeur, 2003).

Para entrar en una redundancia más simplificada, diré que el proceso de comunicación se configura básicamente por cuatro factores que se interrelacionan entre sí, estos son: la existencia de un emisor, de un receptor, de un canal de transmisión y la retroalimentación. 


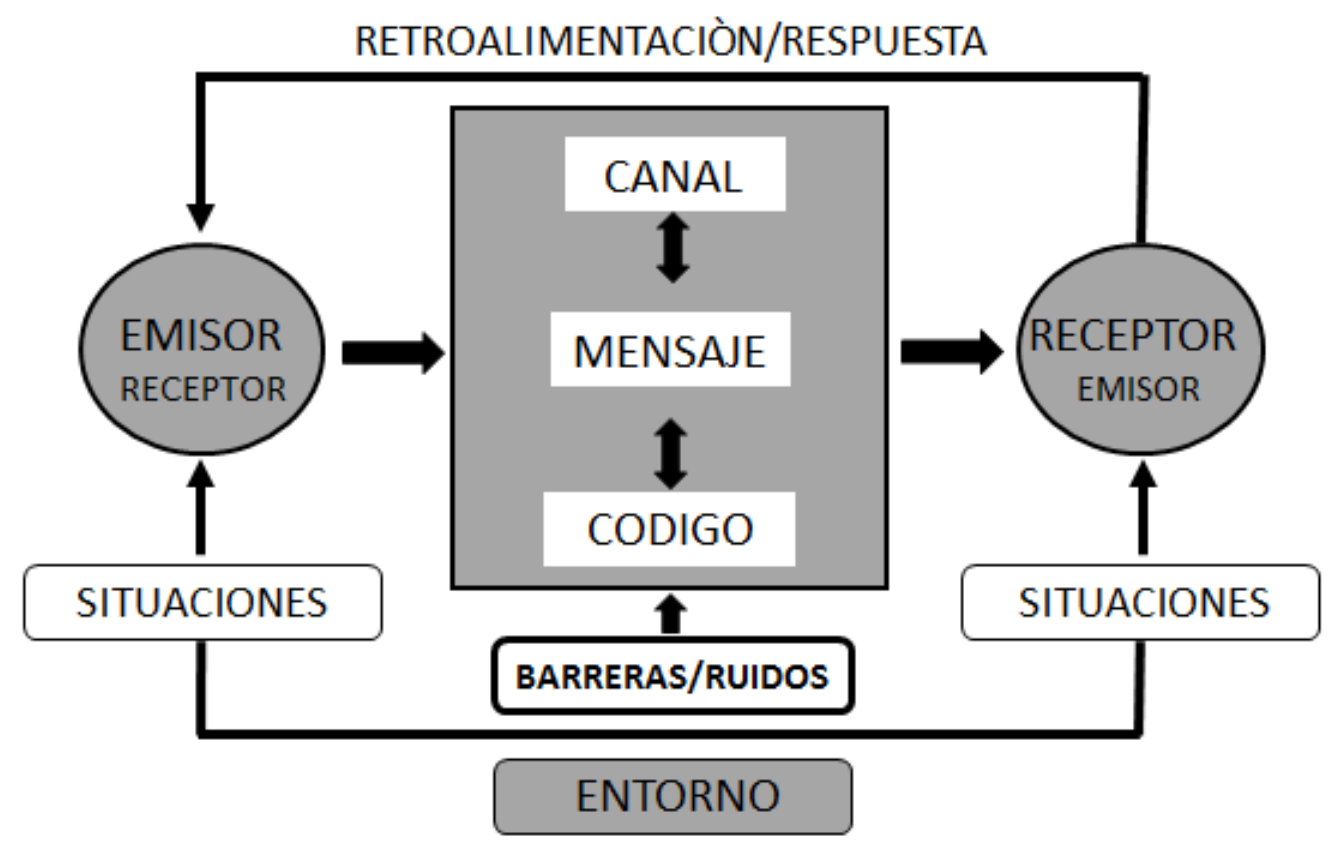

Veamos cómo opera el sistema: El emisor experimenta la necesidad de comunicar algo para lo cual elabora el mensaje, lo codifica y emite la información a través del canal de transmisión de la información (que puede ser de diferente tipo). Aquí el receptor recibe la información, la decodifica, reconstruye el mensaje e interpreta la necesidad del emisor. Pero mientras el receptor está recibiendo el mensaje, el emisor influye sobre sí mismo y autorregula sus propias palabras en consonancia a la reacción que advierte en el destinatario, lo que distinguiremos como el proceso de retroalimentación.

El que se dé una comunicación adecuada entre los diferentes elementos que intervienen en el proceso comunicativo, depende del acuerdo de sus integrantes. En este sentido podemos decir que los elementos básicos de la comunicación son el emisor y el receptor como agentes activos y conscientes del proceso. No se puede pensar en una buena comunicación donde el emisor asuma un papel activo y el receptor un papel pasivo (no debemos olvidar que la existencia de una comunicación completa depende de la retroalimentación que le llega al emisor). Además, existen condiciones que favorecen o dificultan la fidelidad de una comunicación y su correcta decodificación. Tenemos: la existencia de experiencias comunes, el contexto presente y la personalidad de quienes participan del proceso comunicativo. 
En cuanto el emisor y el receptor pertenezcan a una misma cultura o subcultura y, por lo tanto, posean más o menos similares experiencias, tendrán entre sí mayores posibilidades de una comunicación (ilusoriamente) efectiva. En el mismo sentido, cuando se dan diferencias culturales los significados suelen ser entendidos según el grupo de referencia y la propia experiencia de los individuos. Es el caso que se da en la comunicación dificultosa entre interlocutores de distinta clase social, cultura o nacionalidad, al poseer códigos lingüísticos propios (o jergas) o connotaciones diferentes para una misma palabra.

El contexto donde se da el proceso es otro de los factores que condicionan el tipo de comunicación. El mensaje puede verse más o menos afectado según se vea o no condicionado el tipo de comunicación no verbal que acompaña a la comunicación verbal. Caso, por ejemplo, de tonos de voz, gestos con los que acompañan la comunicación verbal o distancia entre los interlocutores.

Por otra parte, los rasgos de la personalidad (o características personales) le imprimen a las palabras significados distintos. Por ejemplo, el significado que un niño de autoestima baja le dé a la palabra "poder", “capacidad” o "evaluación" será muy distinto de aquél que posea una autoestima alta. Aquí, y en la misma dirección, me referiré a una de las barreras más importantes que influyen en una buena comunicación: el prejuicio. El prejuicio, definido como una actitud sin fundamento en la experiencia, genera en los individuos ciertos comportamientos a determinados grupos sociales diferentes al grupo en que uno está incluido. El prejuicio genera una tendencia negativa a todo grupo que consideremos extraño. Paradojalmente el prejuicio une a los miembros de un mismo grupo y a la vez separa de otros. Por ejemplo, el comportamiento que tenemos hacia los gitanos, hacia los pobres, hacia las personas con discapacidad, etc. (Moscovici, 1991).

Tomando en consideración los factores antes señalados, podemos decir que se puede dar, por lo menos, tres formas especiales de incomunicación: la seudocomunicación, el mero entendimiento y la comunicación incompleta.

La seudocomunicación se da cuando los interlocutores creen que se ha dado una comunicación eficaz cuando en realidad han entendido mensajes diferentes. 
El mero entendimiento se da cuando existe una comunicación fragmentada. En este caso los interlocutores creen haber tenido una comunicación completa, cuando en realidad ha habido comprensión de lo comunicado, pero no de todo lo comunicable.

La comunicación incompleta se da cuando la dirección del mensaje es única (unidireccional), sea porque no existe retroalimentación o bien porque simplemente el emisor no espera contestación o porque no la escucha.

Comunicación en las comunidades (organizaciones) educativas.

Llevando las anteriores distinciones al contexto de comunidades educativas, debo decir que en la relación profesor-estudiante se da un acto de interacción humana que configura una comunicación o incomunicación específica que repercute en el proceso educativo, esencialmente en la enseñanza (por parte del profesor) y en la calidad de los aprendizajes (por parte de los educandos). Para enfatizar en esto, haré tres observaciones de carácter hermenéutico-críticas, apoyándome en los planteamientos de Carrión (2003):

Primera observación. Dado que los estudiantes de ciertos grupos sociales están insertos en una cultura determinada que condiciona sus valores, actitudes, formas de pensar, de comportarse y, por supuesto, su propio código lingüístico se verá, una vez que ingrese a la institución educativa envuelto en una red de interacciones diferentes a las que conoce, según los grupos sociales presentes, lo que facilitará o dificultará sus procesos de comunicación y, que, por lo tanto, incidirá en la calidad de sus aprendizajes.

Segunda observación. En el contexto de las vidas diarias de los estudiantes, en interacción con los otros, se legitiman ciertos códigos de comunicación no verbal y un estrato lingüístico propio o con connotaciones semánticas bastante particulares, que facilitan la comunicación entre los miembros de su grupo de referencia, pero la hacen más difícil con otros grupos. De igual modo, por un proceso de socialización en interacción con su grupo, los participantes aprenden una determinada forma de comportarse adecuada a la colectividad que le rodea, por un proceso basado principalmente en la imitación, primero de los miembros de su familia, amigos, vecinos y muy posteriormente por un proceso de socialización en las comunidades educativas, pero aquí el estudiante ya cuenta con un conjunto de comportamientos internalizados que son valorados por los miembros de su grupo (caso aparte lo constituyen los medios de comunicación de masas). Al ingresar a la 
escuela el educando se encuentra en un contexto diferente a la realidad habitual en la que había vivido. En este momento le comienzan exigencias distintas, que más profundas le serán si existe una distancia mayor entre su grupo de referencia y el grupo actual en el que está inserto.

Tercera observación. Como la práctica educacional tradicional continúa centrada en la enseñanza y no en el proceso de aprendizaje, facilita que se den procesos de incomunicación no conscientes, que llevan a los involucrados en el proceso educativo a creer que los problemas de aprendizaje de los estudiantes se focalizan sólo en él o ella (modelo organicista). Esto lleva a que se construya una dinámica particular en torno al educando y su familia, donde la comunidad educativa (y los profesionales de la educación) se desentienden de la/s realidad/es. Se comienza a ver al estudiante, entonces, como un problema, un educando con dificultades que necesita de profesionales especializados, de atención especial, de un currículum especial; cuando en verdad lo único especializado que se requiere es que sea escuchado y se entable una relación dialógica. Se necesita en las comunidades educativas, sobre todo de sectores pobres o en vulnerabilidad, que profesor y estudiante puedan establecer una verdadera comunicación consensuada.

Atendiendo a lo anteriormente señalado, la concreción del currículum debe estar centrada en el proceso de aprendizaje de cada estudiante; es decir, que sea consecuente con una postura constructivista del desarrollo y del aprendizaje, que determinarán los contenidos de la enseñanza y el operar del profesor. Para tal efecto, el planeamiento curricular debe partir desde el propio estado y condiciones de desarrollo del individuo y de sus esquemas de conocimiento previo (determinado por su cultura) para, desde ahí, provocar nuevos estados de desarrollo y conocimientos culturalmente organizados. Así, el proceso de aprendizaje estará centrado en el/la estudiante y cómo lograr que adquiera nuevos esquemas de conocimiento que le permitan la adquisición de nuevos aprendizajes, lo que supondrá la adecuación del currículum a las características y necesidades educativas de cada estudiante (propósito del Diseño Universal de Aprendizajes, DUA, contenido en el Decreto $\mathrm{N}^{\circ} 83$ ), considerando que deben promover el desarrollo integral de la persona, según los fines que la propia sociedad se ha trazado para cada uno de sus miembros. 
Si los distintos miembros que constituyen la institución escolar, específicamente profesores y estudiantes, logran un cierto grado de autonomía en el proceso educativo, se podrá definir un currículum que no esté ajeno a la realidad más próxima de sus integrantes, donde tanto el profesor como el aprendiz, reflexionen permanentemente de la práctica educativa y el currículum se construya con un alto grado de participación, acorde a las características del o la estudiante como parte integrante de la realidad social de la sala de clases, lo que se conseguirá si -como dice Giroux (2001)- entendemos que el conocimiento ha de cuestionarse y situarse en el contexto de unas relaciones sociales del aula que permita el dialogo, el debate, el acuerdo y, en fin, todas las comunicaciones necesarias para construir diseños universales de aprendizajes en ámbitos de diversidad educativa; condición sin la cual no podríamos distinguir escuelas orientadas por una educación inclusiva.

\section{9.- Conclusiones}

Diferentes investigadores (Argyris, 2000; Arredondo, 2002; Carrión, 2003) le dan mucha importancia al manejo de habilidades comunicativas (escucha activa, mensajes claros, flexibilidad comunicativa, asertividad, empatía cognitiva y emocional, respuestas prudentes y otras), para la conservación de una interrelación adecuada y eficaz entre sus miembros. El desarrollo de estas habilidades son tareas imprescindibles en el quehacer de todo líder organizacional y, en específico, en todo líder educativo con sentido transformacional. Para este acometido se puede recurrir a los hallazgos de las neurociencias en general, pero más finamente en la neurolingüística (Sambrano, 2001) y en la neurocomunicación (Nick y Ledesma, 2015).

Para que todo líder aprenda nuevas habilidades comunicativas con independencia de la organización desde donde surja la necesidad, debe darse el principio de querer aprender dichas habilidades y responsabilizarse por la transformación personal que conlleva el desarrollo de estas habilidades, puesto que todo líder es -a la vez- elemento estructural de la organización y entorno de esa organización perteneciente a una clase particular y distintiva por sus comunicaciones que conserva para mantener su viabilidad. En otras palabras, un líder es parte (estructura) y entorno (alteridad) de la organización por su capacidad comunicativa. Por ello, debe ser doblemente consciente de su responsabilidad para provocar transformaciones desde su dominio del manejo de habilidades comunicativas en 
las interacciones humanas que conforman sistemas sociales. Estas habilidades: rapport, empatía, flexibilidad, asertividad, escucha activa y otras, han sido tema central de un sinnúmero de investigaciones y teóricos que han escrito al respecto. Entre ellos tenemos a Robbins (1998), De Bono (1999), McDermott y O’Connor (1999), Argyris (2000), Ribeiro (2000), Sambrano (2001), Arredondo (2002), Arocha (2003), Senge (2005), Carnegie (2011), Goleman (2015), Sandoval (2016), entre otros muchos que han puesto el centro gravitacional de todo líder organizacional en las diferentes habilidades comunicativas y socio-afectivas para el logro de una sinergia y trabajo en equipo cooperativo que, en los sistemas educativos de orientación inclusiva, debe tener como objetivo central la potenciación de los aprendizajes posibles para el mejoramiento de la calidad de vida de cada uno de sus integrantes según el rol que desempeñan dentro de la organización (Berger, 2012).

Con todo, quiero finalizar con esta frase de Bernard Shaw: "El problema más grande de la comunicación es la ilusión de que ha tenido lugar", cuando en sí sólo se trata de un acuerdo de coordinaciones conductuales entre miembros de una determinada comunidad o sistema social. Al ser un acuerdo entre miembros o interlocutores, da lo mismo si son o no son de la misma etnia, raza, condición social, género, religión, partido político, capacidad, edad, estatus, etc. Lo que importa es el acuerdo o no entre los miembros de un sistema social para conservar o no su viabilidad. Así expuesto, la inclusión como realización en un campo valórico, tiene menos importancia que en el campo biológico-político, puesto que a mayor inclusión y mayores acuerdos comunicativos, mayor es la viabilidad del sistema social porque mayor es su capacidad de adaptabilidad a entornos constantemente cambiantes. Si lo único seguro entre sistema y entorno es el cambio, deseo plantear que todo sistema social, y en particular el educativo, debe desarrollar las siguientes capacidades:

.- saber vivir en la incertidumbre.

.- lograr la flexibilidad de creencias.

.- mantener una escucha activa.

.- planificar aprendizajes variados y permanentes. 
.- valorar el trabajo en equipo.

.- desarrollar relaciones dialógicas.

-- respetar los acuerdos y actuar en consecuencia.

Referencias bibliográficas

Argyris, C. (2000). Comunicación Eficaz. España: Ediciones Deusto.

Arocha, L. (2003). PNL Organizacional. Caracas: Editorial Júpiter.

Arredondo, L. (2002). Sea un Comunicador Excelente. Madrid: McGraw.

Berger, P. (2012) Introducción a la sociología. México: Limusa.

Carnegie, D. (2011) Las 5 habilidades esenciales para tratar con las personas. Buenos Aires: Sudamericana.

De Bono, E. (1999). Como Atraer el Interés de los Demás. Barcelona: Editorial Paidós.

Dilts, R. y Epstein, T. (1999). Aprendizaje Dinámico con PNL. Barcelona: Editorial Urano.

Fenger, N. y Ledesma, M. (2015). La neurocomunicación avanzada. Quito: Editorial Jurídica del Ecuador.

Fernández, H. y Damnke, J. (1998) La Comunicación Humana. México: Editorial McGrawHill.

Folkman, J. y Zenger, J. (2002): http://www.grupo-pya.com/es/partner/zenger-es-es-es/

Gardner, H. (1994) Estructuras de la mente. La teoría de las inteligencias múltiples. México: FCE.

Gardner, H. (1998) Mentes líderes: Una anatomía del liderazgo. México: Paidós.

Giroux, H. (1990) Los Profesores como intelectuales. Hacia una pedagogía crítica del aprendizaje. Barcelona: Paidós-MEC.

Giroux, H. (2001) Cultura, política y práctica educativa. México: Graó.

Goleman, D. (2015) Cómo ser un líder. Barcelona: Ediciones B. 
Izuzquiza, I. (1990). La Sociedad sin Hombres. Niklas Luhmann o la teoría como escándalo. Barcelona: Editorial Anthropos.

Levinas, E. (2006) Humanismo del otro hombre. México: Siglo Veintiuno editores.

Lorenz, K. (1995) La otra cara del espejo. Barcelona: Plaza \& Janes.

Luhmann, N. (1990) Sociedad y sistema: la ambición de la teoría. España: Paidós.

Luhmann, N. (1998) Sistemas Sociales. Lineamientos para una Teoría General. México: Anthropos.

Manosalva, S. (2017) Identidad y diversidad: los sistemas educacionales como mecanismos de diferenciación social. Ediciones CEU. Santiago de Chile.

Maturana, H. (1992) El sentido de lo humano. Hachette. Stgo. de Chile.

Maturana, H. (1992) Emociones y lenguaje en educación y política. Santiago de Chile: Hachette.

Maturana, H. (1996) La Realidad: ¿Objetiva o construida? II Fundamentos biológicos del conocimiento. México: Anthropos.

Maturana, H. y Varela, F. (1972) De Máquinas y Seres Vivos. Santiago de Chile: Universitaria.

Maturana, H. y Varela, F. (1992) El árbol del conocimiento. Las bases biológicas del entendimiento humano. Editorial Universitaria. Santiago de Chile.

Mcdermott, C. y O'Connor, J. (1999). PNL para Directivos. Barcelona: Editorial Urano.

MINEDUC (2015) Decreto N 83. MINEDUC, Chile.

Moscovici, S. (1991) La sicología social (I y II). Barcelona: Paidós.

O'Connor, J. y Seymour, B. (1999) PNL para Formadores. Ediciones Urano. Barcelona, España.

Ribeiro, L. (2000) La comunicación eficaz. España: Urano.

Ricoeur, P. (2003) Teoría de la interpretación. Discurso y excedente de sentido. Buenos Aires: Siglo XXI. 
Sambrano, J. (2001). PNL para Todos. Venezuela: Editorial Melvin.

Sandoval, C. (2016) De jefe a líder. Santiago de Chile: Aguilar.

Senge, P. (2005) La Quinta Disciplina. Argentina: Granica.

Tannenbaum, W. y Massarick, J. (1971) Liderazgo y Organización: Introducción a la ciencia del comportamiento. Buenos Aires: Edit. Troquel.

Veliz, F. (2011) Comunicar. Barcelona: Gedisa. 